\title{
Gender perspective on information literacy: An interdisciplinary and multidimensional analysis within higher education settings
}

\author{
María Pinto (a), Dora Sales (b), Rosaura Fernández-Pascual (c) \\ (a) Department of Information Science, University of Granada, 18071 Granada, Spain \\ (b) Department of Translation and Communication, University Jaume I, 12071 Castellón, Spain \\ (c) Department of Quantitative Methods for Economics and Business, University of Granada, 18071 \\ Granada, Spain
}

\begin{abstract}
Gender is a sociological variable that needs further attention in information literacy studies. This study uses a multidimensional subjective-objective approach to examine the gender differences in the information literacy learning process in a sample of students from different social sciences degree courses at five Spanish universities. Surveys are used to measure the belief in importance (BI) and self-efficacy (SE) they assign to a series of basic information competencies, grouped into the categories of searching, evaluation, processing and communication-dissemination, as well as the levels of knowledge $(\mathrm{KN})$ they have about them. Non-parametric methods and factor analysis are used to evaluate the gender similarities and differences. Latent structures show no relevant differences by gender in perceptions (BI and SE), but different patterns are found in knowledge (KN) regarding the acquisition of the key information competencies. To overcome possible stereotypes and contribute to the construction of an all-inclusive perspective that fosters an awareness of the value of equality, it is necessary to incorporate the gender perspective in information and knowledge management studies. There is still little research in this field, and this study opens some paths for further works.
\end{abstract}

\section{Introduction}

Research within the field of information literacy (IL) has been undertaken from a number of different approaches and hence studies have been conducted on a broad variety of topics, such as certain background aspects, informational behaviour, information needs, knowledge management, and even some sociological characteristics. All of these are key factors in the subsequent design of IL training programmes. The 
Association of College and Research Libraries (ACRL, 2000) provided a well-known definition of information literacy, understood as a set of abilities requiring individuals to "recognize when information is needed and have the ability to locate, evaluate, and use effectively the needed information". This study is aligned with the aforementioned definition of IL, as a starting point.

IL forms the basis for lifelong learning. It is common to all disciplines and areas, to all learning environments and levels. It enables learners to manage information and to improve their research, become more self-directed, and assume greater control over their own learning process. Both university libraries and faculty have focused mainly on information literacy training programs, to cover the use of information from a wide perspective, including competencies (that is, a combination of knowledge, skills and attitudes) related to search, assessment, processing, dissemination and ethical information management (Bawden and Robinson, 2009; Chen and Lin, 2011; Lee, 2010).

Recently, new perspectives have also opened, as the interrelationship between IL and other literacies, understood as media and information literacy or multiliteracy (Grizzle et al, 2014); the growing presence of mobile technologies (Clark et al, 2017), or the revised conception of IL, now based on frameworks that enhance the social relevance of this field (Julien, Gross and Latham, 2018).

\section{Problem statement}

One sociological variable of great interest is that referring to the possible dissimilarities that may arise in the field of information competencies learning due to gender differences, in other words, if by disaggregating responses by gender (female or male) differences are detected. In this regard Taylor and Dalal $(2017,93)$ state that: 
It may be a revelation to some that gender differences in information literacy may exist. Identifying gender-specific characteristics of student information searchers will provide further clarity on how students search for information. The specifics of these gender differences can provide guidance to instructors in the preparation of gender-aware information literacy instruction.

Whereas Taylor and Dalal focus on the gender perspective in relation to searching for information, the main aim of this research is to determine the gender differences in the IL learning process from a multidimensional perspective, which has not been applied hitherto. Therefore, this study pursues:

1. To examine the patterns of informational behaviour from the subjective-objective perspectives of learning by categories. The study intends to analyse students' perceptions of belief-in-importance (BI) and self-efficacy (SE), in order to test whether there are any significant gender differences. Furthermore, it also seeks to analyse the category scores achieved from the perspective of knowledge (KN), in order to determine the levels of information competency and to test whether there are any significant differences between genders.

2. To explore the gender panorama according to academic degree courses.

3. To identify what competencies support the latent structures and can be considered the core IL competencies and, additionally, to test whether there are any important gender differences within these latent structures.

\section{Literature review}

Taking into account that the use of a gender perspective on information literacy is an emerging research sphere, it is therefore worthwhile to mention other studies that make up a thought-provoking panorama, though they are not directly related to the scope and 
methodology covered in this study. As stated before, the multidimensional perspective developed here in order to determine the gender differences in the IL learning process has not been carried out in any previous study. In this regard, it is considered that it might be valuable for potential readers to offer a succinct overview of research conducted to date from a gender perspective on IL, and, specifically, on gender differences in IL learning.

\subsection{An overview of research on IL that incorporates a gender perspective}

Within the specific context of IL scarce research has been conducted on the discipline of women and gender studies or that at least takes the gender variable into account. The Association of College and Research Libraries (ACRL) has compiled literature on the issue in order to increase the visibility of women's studies collections and services in academic and research libraries, as well as to promote them and offer them support (ALA/ACRL/Women \& gender studies section). It has also drawn up a research agenda on women and gender studies librarianship to which it adds topics of interest or that are currently under development (ALA/ACRL/Women \& gender studies section, Research agenda 2012), including information literacy and women and gender studies in higher education (ALA/ACRL/Women \& gender studies section, information literacy and women and gender studies in higher education 2012).

Among the studies conducted in recent years that address different research topics related to the gender perspective regarding IL and knowledge management, mention should be made of the pioneering studies by Huston and Yribar (1991), on the potential impact that the development of women's studies programmes and women's studies collections may have on information literacy education; Golian and Pellen (1996), on 
how academic librarians should adopt information literacy as a priority regarding the responsibility of helping re-entry women - and other non-traditional students - to acquire information literacy skills; and that of Volman (1997), on patterns of behaviour and gender-linked attitudes within the learning context of the subject entitled information and computer literacy in secondary education.

For their part, authors such as Weeg (1997), Wilkinson (2004; 2006) and Simoes and Gray (2009) have developed interdisciplinary experiences involving training tasks used for information literacy in courses on women's and gender studies. Dennis (2001) analyses the use of IL classroom activities in women's studies classes at university to show how these activities help academic librarians to achieve parity with faculty members of the discipline. Roy Dholakia (2006) studies the role of gender and its relationship with Internet use in the home. Broidy (2007) focuses on the creation of a course to explore the changing nature of information and to explode the myth of its neutrality by combining principles of information literacy, essential feminist principles, and critical theoretical approaches. Gilley (2007) offers a critical approach to information-seeking in the field of women's studies to improve it and make it more effective. Gillard, Mitev and Scott (2007) explore a private-public training initiative and its impact on the socially excluded, specifically lone women parents. Radeloff and Bergman (2009) delve into the use of media literacy activities to foster critical thinking in women's studies and feminist curricula. Baro and Fyneman (2009) administered the "Information literacy among undergraduate students of social sciences questionnaire" (ILUSSSQ) to bachelor's degree students at Niger Delta University (Nigeria), finding significant differences in favour of male students over their female counterparts as 
regards information competencies and digital culture. And Grizzle (2014) puts forward how media and information literacy could be engaged to encourage gender equality in and through media.

\section{2. $\quad$ Previous research on gender differences in IL learning}

Furthermore, there is previous inspiring research that, from diverse viewpoints and methodologies, has also studied gender differences in the context of IL learning, as it is the purpose here. It is important to mention the ground-breaking contribution by Fields (2001), on gender differences in epistemological development and what this implies in the teaching of information literacy, betting on the development of new instructional strategies for building up information literacy in women students.

Burdick (1996), Steinerova and Susol (2007), and Lim and Kwon (2010) centre their studies on gender differences in information behaviour and the use of sources of information: Burdick's (1996) study with high school students shows that the differences between female and male students are not related to their ways to perform information searching tasks but to topics covered, task perception and affective experience. Steinerova and Susol (2007), based on a study of library users in Slovakia, also find gender differences, showing that women prefer to apply collaborative information use and tend to develop a pragmatic way of information use. Lim and Kwon (2010) examine gender differences in information behaviour specifically regarding Wikipedia among undergraduate students, and show that female students are more cautious and do not use Wikipedia as much as male students.

Kwon and Song (2011) delve into the self-perception of information competencies of undergraduate students from a gender perspective, and their results find that openness 
to experience is a female-specific trait. Liu and Sun (2012) study gender differences on the information literacy of science and engineering undergraduates, applying tests that show gender differences regarding information consciousness, information competency and information ethics. Lin, Shih and Lu (2013) analyse gender differences among undergraduate students in the results of some tests from the Certification Pathway System (CPS), and their findings show gender differences in all three aspects of ICT (information and communication technologies) covered in the study, namely computer fundamentals, key applications, and living online. More recently, Taylor and Dalal (2017) focus on gender differences in information literacy skills, and more specifically with regard to undergraduate students' critical perceptions about sources of information on the Internet. One of their findings is that female students are more critical and discerning about evaluating sources.

As can be seen, the gender perspective opens up a number of lines of research within the field of information and knowledge management studies and, especially, in the learning of competencies under the IL educational paradigm. The present study aligns with this field and aims to analyse the information literacy learning process and the gender differences within a sample of university students from different degree courses and Spanish universities, from a multidimensional perspective that has not been developed in previous studies.

\section{Methodology}

This section is structured in four parts, devoted to the instruments, sampling methods, sample characteristics, and data analysis methods being used.

\subsection{Instruments}


Two instruments were used for data collection: IL-HUMASS and EVALCI-KN. Both were developed at the University of Granada, during the years 2008-2015, under the direction of María Pinto as the lead researcher for the multidisciplinary team.

Psychometric properties -validity and reliability- have been widely verified in previous studies (Pinto, 2010, 2011; Pinto and Fernández-Pascual, 2017). IL-HUMASS focuses on students' perceptions of IL competencies through three subjective scales: belief-in-importance (BI), self-efficacy (SE) and preferred learning source (LS). But this last scale, which is not quantifiable like the other two, is not included among the objectives of this research. While the concept of BI refers to the levels of students' awareness on the relevance of a series of IL competencies, SE refers to students' estimated levels of own knowledge/skill on these capabilities. Measuring of BI and SE is based on a Likert scale from 1 to 9 : $<5$ (low), $>5-6<$ (moderate), $>6-7<$ (normal), $>7-8<$ (high), >8 (excellent). EVALCI-KN focuses on students' actual levels of knowledge (KN) on the same twenty-six IL-HUMASS items, with five closed answers options for each of them. In order to avoid distortions, the choices don't know/don't answer were also offered. A Likert scale of 1 to 5 was used to assess the least to most appropriate responses. In order for this scale to be comparable with that of IL-HUMASS, values of 1-9 were transformed and downward rounding was chosen to obtain greater discrimination between the scores, leaving it as follows: not adequate (1), partially adequate (3), quite adequate (5), adequate (7) and totally adequate (9) (Pinto and Fernández-Pascual, 2017). Both instruments consist of four informational categories - searching, evaluation, processing and communication-dissemination - and twenty-six item measures (see ILHUMASS on Annex. EVALCI's original Spanish survey is available online at 
http://infocompetencias.org/evalci/test-evaluacion.php. Due to the fact that it offers diverse tasks that have to be performed online, it cannot be provided otherwise). What makes these scales suitable for measuring how successfully the IL competencies have been achieved is that they capture the complex multidimensional nature of the abovementioned subjective (BI and $\mathrm{SE}$ ) and objective $(\mathrm{KN})$ variables. A brief explanation of the categories on IL competencies is displayed below:

- Searching. Concerning the use of different search tools (in printed, electronic or informal sources or from the Internet, in catalogues and secondary sources, related to the realm of terminology and search strategies).

- Evaluation. With regard to the quality of the resources (the main ideas, whether they are up-to-date, the relevance of authors and institutions, etc.).

- Processing. On the capacity to organise and manage data (recognise the textual structure, outline and summarise, use database and reference management software, install and use statistics programs and spreadsheets).

- Communication-Dissemination. On the generation of new information (communicating in public, communicating in other languages, writing different kinds of academic documents and presentations, being familiar with the code of ethics of the field of work and the laws concerning the use and ownership of information, and knowing how to disseminate information on the Internet).

\subsection{Sampling methods}

The sample population consisted of students at five Spanish public universities (Complutense of Madrid, Málaga, Murcia, Jaume I, and Granada) in the year 2014. It included third and fourth year students in eight degrees: information science, 
audiovisual communication, journalism, psychology, primary education, pedagogy, social work, and tourism.

This research considered the total number of students enrolled, and the number of third and fourth-year students in the eight degrees and the five participating universities, which allowed us to calculate -by stratified sampling with proportional allocation- the optimal number of students needed to estimate the mean score with an accuracy of 0.5 points. Three strata: -students per university, students per degree program and students per course- were regarded. Finally, the size of each stratum of the sample was increased by $20 \%$ in order to prevent potential non-response bias. The selected universities were the five participating universities in the National Research Project funded by the Spanish Ministry of Education that holds this study.

The questionnaires were administered online, usually in computer labs. The teaching staff of the courses and degrees involved in the research provided support.

\subsection{Sample characteristics}

Although 1836 surveys were initially collected, after data cleaning the sample was reduced to 1575 valid surveys (response rate of $85.78 \%$ ). The population of students enrolled in $3^{\text {rd }}$ and $4^{\text {th }}$ years was 15151 (sampling ratio 10.39\%). These courses were selected to try to know the IL level of more advanced students, already in the second cycle of their respective degrees.

Altogether 1575 responses - distributed between the third (1101) and fourth (474) years - were gathered. Overall, there were 500 male and 1075 female responses (Table 1). Gender parity index: 2.15 (UNESCO 2009). The average age was 22.23 years, with a range between 19 and 59 years. There is great homogeneity in the age of the 
participants. Therefore, age has not been included as a control variable. $97 \%$ of those surveyed are under $25,2 \%$ are between 25 and 30 , and only $1 \%$ of the sample is over 30.

\begin{tabular}{|l|cc|cc|}
\hline & \multicolumn{2}{|c|}{ Male } & \multicolumn{2}{c|}{ Female } \\
\hline Degree & Number & $\%$ & Number & $\%$ \\
\hline Audiovisual Communication & 100 & 20.0 & 98 & 9.1 \\
Education & 135 & 27.0 & 235 & 21.9 \\
Information Science & 44 & 8.8 & 78 & 7.3 \\
Journalism & 86 & 17.2 & 150 & 14.0 \\
Pedagogy & 22 & 4.4 & 91 & 8.5 \\
Psychology & 42 & 8.4 & 181 & 16.8 \\
Social Work & 23 & 4.6 & 114 & 10.6 \\
Tourism & 48 & 9.6 & 128 & 11.9 \\
Total & 500 & 100.0 & 1075 & 100.0 \\
\hline
\end{tabular}

Table 1: Sample distribution by degree and gender

\subsection{Data analysis methods}

To investigate gender differences with regard to dimensions, categories, degrees, competencies and latent structures, data were analysed. Various methods of descriptive statistic, bivariate inferential test, and confirmatory factor analyses (CFA) were used along the various research steps. IBM SPSS Statistic 22, and Microsoft Excel 2013 were an invaluable help. As normality was not accomplished, the use of non-parametric techniques was applied to study the possible gender differences in the BI (belief-inimportance), SE (self-efficacy) and KN (actual knowledge) dimensions. Results were analysed considering competency categories (searching, evaluation, processing and communication-dissemination).

In order to satisfy the first objective, the Mann-Whitney U test was performed on the IL categories that showed different gender behaviours in order to compare those differences. As for the second objective, the Kruskal-Wallis test (an alternative to ANOVA) was carried out to conclude whether there were any statistically significant 
differences among degree programmes. Lastly, the factorial analysis technique was applied with the aim of gaining a deeper understanding of the latent structures and in order to evaluate the similarities and differences between genders in the three dimensions under analysis. This type of analysis facilitated the identification of latent dimensions, called factors, which might underlie and explain the inner structure of the IL categories.

\section{Results}

Results have been organised in the following four sections: internal consistency reliability; gender differences by dimension and category; gender differences by academic degree; and gender comparison regarding latent structures.

\subsection{Internal Consistency Reliability}

The scales employed here had previously been widely validated by other studies (Pinto 2010, 2011; Pinto, Fernández-Pascual and Puertas 2016). The Cronbach's alpha coefficients in the present study were 0.938 and 0.718 for IL-HUMASS and EVALCI respectively, which confirm a good level of reliability and high internal consistency (Cho and Kim, 2015; Taber 2018). The scales' reliability of the instruments is examined by calculating the Cronbach's alpha coefficient for each category (Table 2). All the values exceed the recommended minimum of 0.7 (Nunnally, 1978).

\begin{tabular}{|l|l|c|c|}
\hline Instrument & Category & Cronbach's alpha & Scale if some item is deleted \\
\hline ILHUMASS & Searching & 0.864 & $0.852-0.861$ \\
\hline & Evaluation & 0.834 & $0.812-0.826$ \\
\hline & Processing & 0.801 & $0.772-0.808^{*}$ \\
\hline & Communication/ dissemination & 0.789 & $0.77-0.798^{* *}$ \\
\hline EVALCI-KN & Searching & 0.710 & $0.692-0.711^{* * *}$ \\
\hline & Evaluation & 0.726 & $0.701-0.720$ \\
\hline & Processing & 0.706 & $0.696-0.708^{* * *}$ \\
\hline & Communication/ dissemination & 0.707 & $0.698-0.706$ \\
\hline & \multicolumn{2}{|l|}{${ }^{*}$ The scale improves if the item SE-19 is deleted; ${ }^{* *}$ The scale improves if the item BI-21 is deleted } \\
\hline${ }^{* * *}$ The scale improves if the item KN-3 is deleted; ${ }^{* * *}$ The scale improves if the item KN-18 is deleted \\
\hline
\end{tabular}


Table 2. Cronbach's alpha in instruments and categories

\subsection{Gender differences by dimension and category}

As the sample is not normally distributed (Kolmogorov Smirnof, $p<0.05$ ), nonparametric interpretation methods were employed. Specifically, to compare differences between male and female replies, the Mann-Whitney $U$ test is used to test whether two independent samples of observations are drawn from similar or identical distributions.

Taking into account the gender of the students surveyed, the p-values obtained for each dimension and category make it possible to detect those dimension-category pairs in which statistically significant differences arise (Mann-Whitney $U, p<0.05$ ) between women and men (Table 3).

\begin{tabular}{|c|c|c|c|c|c|c|c|c|c|}
\hline \multirow[b]{3}{*}{ Category } & \multicolumn{9}{|c|}{ Dimension } \\
\hline & \multicolumn{3}{|c|}{$\mathrm{BI}$} & \multicolumn{3}{|c|}{ SE } & \multicolumn{3}{|c|}{$\mathrm{KN}$} \\
\hline & Male & Female & $p$-value & Male & Female & $p$-value & Male & Female & $p$-value \\
\hline Searching & $\begin{array}{c}7.62 \\
(1.41)\end{array}$ & $\begin{array}{c}7.54 \\
(1.30)\end{array}$ & 0.207 & $\begin{array}{c}6.62 \\
(1.59)\end{array}$ & $\begin{array}{c}6.54 \\
(1.62)\end{array}$ & 0.162 & $\begin{array}{c}6.91 \\
(1.81)\end{array}$ & $\begin{array}{c}6.80 \\
(1.87)\end{array}$ & 0.053 \\
\hline Evaluation & $\begin{array}{c}7.85 \\
(1.32) \\
\end{array}$ & $\begin{array}{c}7.79 \\
(1.27) \\
\end{array}$ & 0.801 & $\begin{array}{c}6.68 \\
(1.48) \\
\end{array}$ & $\begin{array}{c}6.65 \\
(1.55) \\
\end{array}$ & 0.541 & $\begin{array}{c}8.26 \\
(1.75)\end{array}$ & $\begin{array}{c}8.31 \\
(1.78) \\
\end{array}$ & 0.146 \\
\hline Processing & $\begin{array}{c}7.45 \\
(1.58)\end{array}$ & $\begin{array}{c}7.39 \\
(1.44)\end{array}$ & 0.439 & $\begin{array}{c}6.31 \\
(1.70)\end{array}$ & $\begin{array}{c}6.18 \\
(1.66)\end{array}$ & $0.045^{*}$ & $\begin{array}{c}6.31 \\
(1.80)\end{array}$ & $\begin{array}{c}5.85 \\
(1.82)\end{array}$ & $0.000^{*}$ \\
\hline Communication/Dissemination & $\begin{array}{c}8.13 \\
(1.21)\end{array}$ & $\begin{array}{c}8.14 \\
(1.14)\end{array}$ & 0.766 & $\begin{array}{c}6.82 \\
(1.59)\end{array}$ & $\begin{array}{c}6.78 \\
(1.63)\end{array}$ & 0.341 & $\begin{array}{c}7.89 \\
(1.86)\end{array}$ & $\begin{array}{c}8.19 \\
(1.75)\end{array}$ & $0.026^{*}$ \\
\hline
\end{tabular}

Table 3. Gender descriptive means, (standard deviations), and p-values concerning dimensions and categories. P-values from Mann-Whitney U test ${ }^{*}$ denotes significant differences).

With regard to searching and evaluation categories, results reveal that mean levels of BI, SE, and KN are similar for female and male students, differences not being statistically significant (Mann-Whitney $\mathrm{U}$ test, $\mathrm{p}>0.05$ ). In processing category, there are two dimensions -SE and KN- in which statistically significant gender differences are observed. In the category of communication, and with regard the KN dimension, statistically significant differences are found, women obtaining a higher score. 
Surprisingly, KN's mean scores are higher than those of SE in both categories and genders. That actual ability of students in a given subject provides higher values than those derived from their own self-esteem on such abilities is not an easily understandable issue. This leads us to think that self-esteem on IL competencies, at least among the surveyed students, should be encouraged (Figure 1).

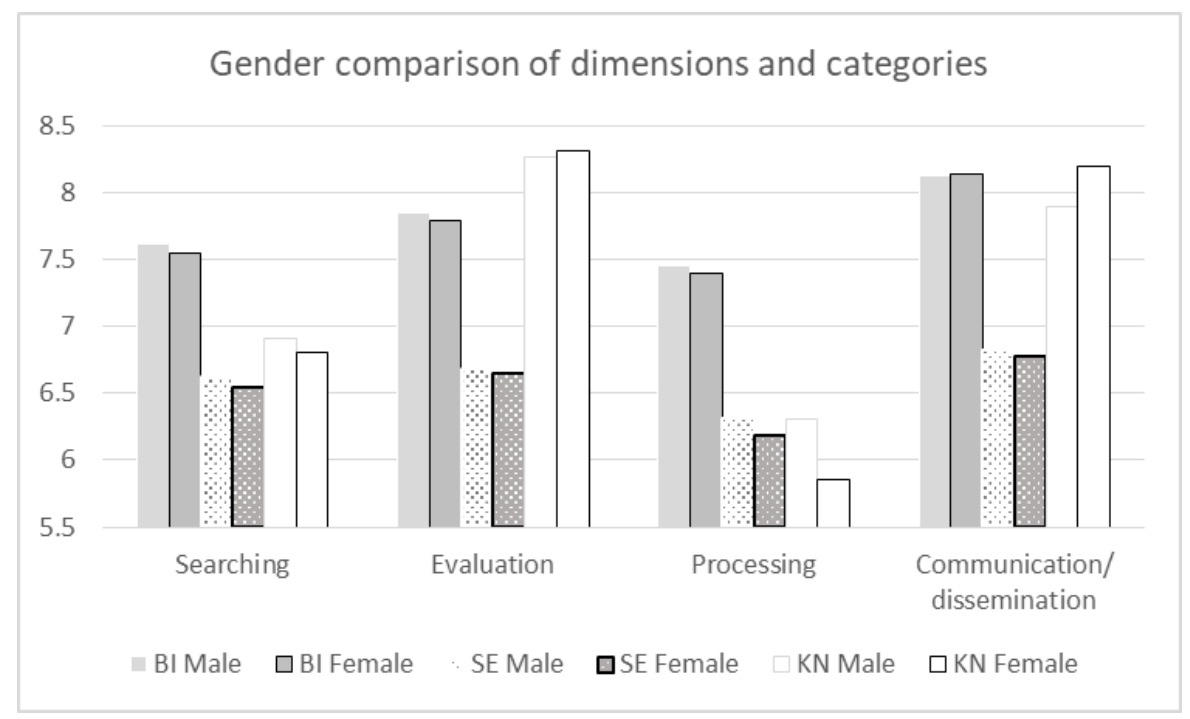

Figure 1. A gender comparison involving mean values in dimensions and categories

\subsection{Gender differences by academic degree}

On comparing the scores of the eight academic degree courses in each of the groups (male and female), results show that the male group presents statistically significant differences (Kruskal-Wallis, $\mathrm{p}<0.05$ ) of mean values scores in almost all the categories and dimensions, except in SE of evaluation and BI of communication/dissemination (Table 4). Similar results within the female group are found, except for BI of processing.

\begin{tabular}{|l|c|c|c|c|c|c|c|c|c|c|c|c|}
\cline { 2 - 13 } \multicolumn{1}{c|}{} & \multicolumn{9}{c|}{ Categories and dimensions } \\
\cline { 2 - 13 } \multicolumn{1}{c|}{} & \multicolumn{3}{|c|}{ Searching } & \multicolumn{3}{c|}{ Evaluation } & \multicolumn{3}{c|}{ Processing } & \multicolumn{3}{c|}{$\begin{array}{c}\text { Communication/ } \\
\text { Dissemination }\end{array}$} \\
\hline Gender & BI & SE & KN & BI & SE & KN & BI & SE & KN & BI & SE & KN \\
\hline Male & 0.001 & 0.001 & 0.000 & 0.048 & $\mathbf{0 . 8 3 2}$ & 0.004 & 0.002 & 0.001 & 0.001 & $\mathbf{0 . 3 4 3}$ & 0.110 & 0.000 \\
\hline Female & 0.002 & 0.001 & 0.001 & 0.000 & 0.001 & 0.002 & $\mathbf{0 . 1 8 9}$ & 0.000 & 0.000 & 0.001 & 0.004 & 0.000 \\
\hline
\end{tabular}


Table 4. P-values from Kruskall-Wallis test according to category, dimension, and gender. Not significant differences in bold.

The degree courses with the highest and lowest scores in the different dimensions and categories, distinguishing by genders, can be seen in the new tables $1 \mathrm{~A}, 2 \mathrm{~A}$, and $3 \mathrm{~A}$ in the Annex. In general, there are highest levels in information science and pedagogy degree courses, and lowest in tourism and social work. Specifically, for the female students, the highest levels are obtained in information science and in journalism, whereas the lowest appear in the social work and the tourism degrees. Taking the three dimensions (BI, SE and KN) into account, information science is the degree course with the highest value in the categories of searching and processing; in the category of evaluation, journalism scored the highest on BI and SE, while psychology does the same on KN. Finally, in the category of communication, the highest values are attained for journalism and audiovisual communication.

\subsection{Gender comparison regarding latent structures}

As previously stated, the third objective of the study is to know the adequacy between the latent structure and the competency categories proposed in the IL-HUMASS and EVALCI instruments. The application of factorial analysis to the twenty-six competencies and to the three dimensions analysed (importance, self-efficacy and real knowledge) makes it possible to discover a series of factors and their conceptual framework. Rather, the aim is to know the latent structures by gender resulting from the interrelations present in the data, as well as the variables that have more weight and therefore can considered as more relevant. 
To this end, a factor analysis technique was applied to reduce the number and composition of the underlying factors, or latent variables. Sub-scales were constructed for each factor and, for clarification purposes, only the variables with a factor loading higher than 0.6, and lower than 0.5 in other factors, are included. KMO (male BI-0.922, SE-0.902, KN-0.813; female BI-0.945, SE-0.931, KN-0.876) and Bartlett's sphericity test (1950) $(\mathrm{p}<0.05)$ confirmed the appropriateness of the factor analysis by each gender, offering evidence of a significant correlation among variables. The results show that fitting a factorial model to the data by gender is a suitable method. According to Kaiser's criterion (1974), factors are included when their eigenvalue is greater than one (Field 2013; Hair, Black, Babin, and Anderson 2010). Varimax with Kaiser normalisation has been considered, as it is a rotation method that diminishes the number of variables with high loadings on one factor, thereby improving the interpretive capacity of the factors obtained. Features of the resulting model for the three dimensions, including percentages of variance explained for the male and female groups, are displayed (Table 5).

\begin{tabular}{|c|c|c|c|c|c|c|}
\hline \multirow[b]{2}{*}{ Factor Models } & \multicolumn{2}{|c|}{ Belief in importance } & \multicolumn{2}{|c|}{ Self-efficacy } & \multicolumn{2}{|c|}{ Actual Knowledge } \\
\hline & Male & Female & Male & Female & Male & Female \\
\hline$\%$ variance explained & 70.18 & 66.87 & 66.98 & 69.87 & 61.75 & 58.69 \\
\hline Optimal number of factors & 6 & 5 & 6 & 6 & 6 & 6 \\
\hline Number of competencies included & 17 & 16 & 17 & 17 & 15 & 18 \\
\hline$\%$ of common competencies & \multicolumn{2}{|c|}{14} & \multicolumn{2}{|c|}{17} & \multicolumn{2}{|c|}{15} \\
\hline
\end{tabular}

Table 5: Main characteristics of the factor analyses

With regard to the belief-in-importance (BI) dimension, the factor analyses carried out confirm the consistency of the four initial categories (Table 6). The competencies belonging to the search, evaluation and processing categories are grouped into factors that fit this categorization, although the relative importance of each of these categories is different when comparing women and men. On the other hand, the competencies of the 
communication-dissemination category are divided into three and two factors, for men and women respectively; these factors refer to communication, ethics and the dissemination of information. The greatest gender differences in the importance of informational competencies (BI) correspond to communication-dissemination of information. Female and male frameworks share fourteen competencies. The most relevant factors are evaluation (42.29\% of explained variance) for male students, and communication (39.61\% of explained variance) for female students. That is to say, while men highly value the relevance of the evaluation of information, women appreciate more the communication of information. Factor loadings and percentages of explained variance are displayed (Table 6). In addition, it is observed that there are seven competencies in the BI dimension that do not load into any of the factors.

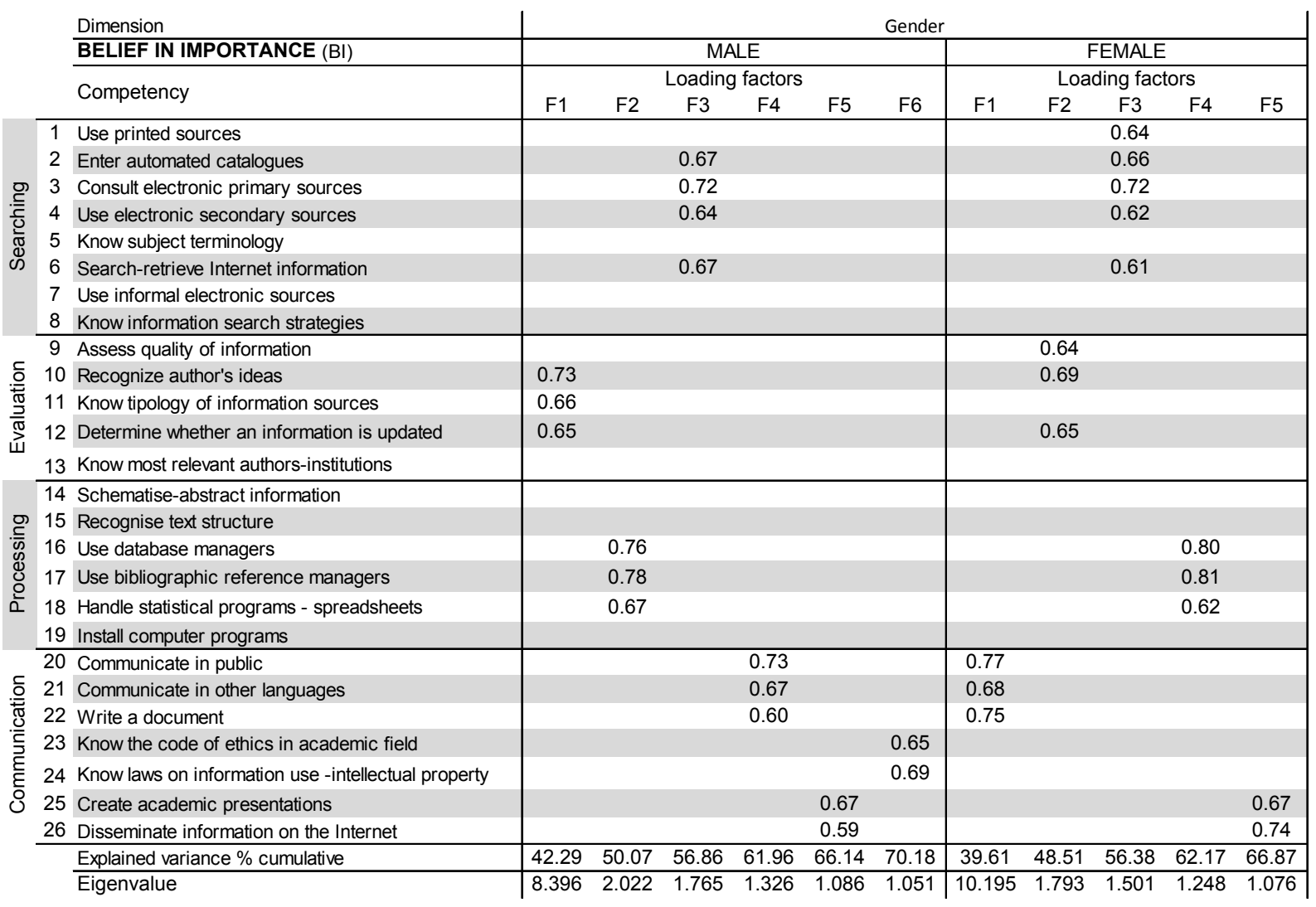


Table 6: Belief-in-importance (BI) factors on IL competencies by gender. Sequenced by order of explained variance

A gender comparison of students' levels of self-efficacy (SE) concerning the twenty six basic competencies allows us to observe a high consistency in the results, not only if the perceptions of both genders are compared but also if the four competency categories contemplated in the instruments used are taken into account (Table 7). The number of factors -six- is also coincident in the gender comparison. The categories of searching, evaluation and processing are faithfully reproduced in the factor analyses carried out. Consistency also affects the competencies involved in each factor, since the coincidence between both groups is complete. The variance explained in each of the two analyses is also quite similar $-66.98 \%$ among men and $69.87 \%$ among women-. These high levels of consistency are reduced in the case of the communication-dissemination category. The self-efficacy of the students in this category (men and women) unfolds in three factors related to communication, ethics and the dissemination of information. From this selfefficacy perspective, the communication-dissemination of information category needs to be nuanced and deployed in both cases. While nine competencies do not participate in either of the two factor analyses, the remaining seventeen participate in both (Table 7). In summary, the comparison of gender in the dimension of self-efficacy (SE) in the performance of informational competencies by the students surveyed shows high levels of similarity and convergence in the four informational categories. 


\begin{tabular}{|c|c|c|c|c|c|c|c|c|c|c|c|c|c|c|}
\hline & & Dimension & & & & & & Ger & nder & & & & & \\
\hline & & SELF EFFICACY (SE) & & & $\mathrm{MA}$ & & & & & & FEN & IALE & & \\
\hline & & & & & Loading & factors & & & & & Loading & factors & & \\
\hline & & Competency & F1 & F2 & F3 & $\mathrm{F} 4$ & F5 & F6 & F1 & $\mathrm{F} 2$ & F3 & F4 & F5 & F6 \\
\hline & 1 & Use printed sources & & & & & & & & & & & & \\
\hline & 2 & Enter automated catalogues & 0.62 & & & & & & 0.78 & & & & & \\
\hline g & 3 & Consult electronic primary sources & 0.62 & & & & & & 0.80 & & & & & \\
\hline 突 & 4 & Use electronic secondary sources & 0.68 & & & & & & 0.72 & & & & & \\
\hline$\frac{\pi}{\sqrt[0]{2}}$ & 5 & Know subject terminology & & & & & & & & & & & & \\
\hline & 6 & Search-retrieve Internet information & 0.67 & & & & & & 0.63 & & & & & \\
\hline & 7 & Use informal electronic sources & 0.64 & & & & & & 0.61 & & & & & \\
\hline & 8 & Know information search strategies & & & & & & & & & & & & \\
\hline & 9 & Assess quality of information & & & & & & & & & & & & \\
\hline 을 & 10 & Recognize author's ideas & & 0.71 & & & & & & 0.72 & & & & \\
\hline$\frac{\bar{\pi}}{\frac{\pi}{\sigma}}$ & 11 & Know tipology of information sources & & 0.65 & & & & & & 0.65 & & & & \\
\hline$\overbrace{111}^{\pi}$ & 12 & Determine whether an information is updated & & 0.61 & & & & & & 0.69 & & & & \\
\hline & 13 & Know most relevant authors-institutions & & & & & & & & & & & & \\
\hline & 14 & Schematise-abstract information & & & & & & & & & & & & \\
\hline ס & 15 & Recognise text structure & & & & & & & & & & & & \\
\hline ") & 16 & Use database managers & & & 0.81 & & & & & & 0.89 & & & \\
\hline ठ & 17 & Use bibliographic reference managers & & & 0.80 & & & & & & 0.74 & & & \\
\hline & 18 & Handle statistical programs - spreadsheets & & & 0.67 & & & & & & 0.64 & & & \\
\hline & 19 & Install computer programs & & & & & & & & & & & & \\
\hline & 20 & Communicate in public & & & & & & 0.64 & & & & & & 0.75 \\
\hline 을 & 21 & Communicate in other languages & & & & & & 0.79 & & & & & & 0.82 \\
\hline . & 22 & Write a document & & & & & & & & & & & & \\
\hline ș & 23 & Know the code of ethics in academic field & & & & & 0.74 & & & & & 0.74 & & \\
\hline$\underline{\varepsilon}$ & 24 & Know laws on information use -intellectual property & & & & & 0.72 & & & & & 0.72 & & \\
\hline రั & 25 & Create academic presentations & & & & 0.71 & & & & & & & 0.66 & \\
\hline & 26 & Disseminate information on the Internet & & & & 0.65 & & & & & & & 0.73 & \\
\hline & & Explained variance $\%$ cumulative & 39.22 & 47.51 & 53.38 & 58.7 & 63.08 & 66.98 & 42.98 & 51.14 & 56.97 & 61.99 & 65.99 & 69.87 \\
\hline & & Eigenvalue & 7.600 & 2.153 & 1.526 & 1.384 & 1.139 & 1.013 & 8.576 & 2.120 & 1.517 & 1.306 & 1.040 & 1.009 \\
\hline
\end{tabular}

Table 7: Self-efficacy (SE) factors on IL competencies by gender. Sequenced by order of explained variance

The dimension of the students' actual knowledge (KN) about a series of basic IL competencies is where the greatest gender divergences are found (Table 8). There are nine competencies that do not participate in factor distribution, while fourteen are common to male and female students. In both cases, the search category is broken down into two factors, relating to actual knowledge of search strategies and the use of information. The factorial load is concentrated in four of the eight competencies of the category. The evaluation category is the only one that maintains its identity after factor analyses in both genders, having reduced its representation to three competencies. The processing category is divided into the group of women, who distinguish between human processing and technological processing. The category of communication is also unfolded, but in both genders, although with very different components in each of them. This same degree of fragmentation was already observed in Pinto and Fernández- 
Pascual (2017), where the authors revealed six latent categories or factors for the KN dimension.

\begin{tabular}{|c|c|c|c|c|c|c|c|c|c|c|c|c|c|c|}
\hline & & Dimension & & & & & & Ger & ider & & & & & \\
\hline & & ACTUAL KNOWLEDGE $(\mathrm{KN})$ & & & $\mathrm{MA}$ & $\mathrm{LE}$ & & & & & FEM & $\overline{\mathrm{ALE}}$ & & \\
\hline & & & & & Loading & factors & & & & & Loading & factors & & \\
\hline & & Competency & F1 & $\mathrm{F} 2$ & F3 & F4 & F5 & F6 & $\mathrm{F} 1$ & $\mathrm{~F} 2$ & F3 & $\mathrm{F} 4$ & F5 & F6 \\
\hline & 1 & Use printed sources & & & & & & & & & & & & \\
\hline & 2 & Enter automated catalogues & & 0.57 & & & & & 0.67 & & & & & \\
\hline 읻 & 3 & Consult electronic primary sources & & & & 0.70 & & & & & & & 0.62 & \\
\hline 突 & 4 & Use electronic secondary sources & & & & & & & & & & & & \\
\hline$\frac{5}{\Phi}$ & 5 & Know subject terminology & & & & & & & & & & & & \\
\hline ळ & 6 & Search-retrieve Internet information & & & & 0.69 & & & & & & & 0.67 & \\
\hline & 7 & Use informal electronic sources & & & & & & & & & & & & \\
\hline & 8 & Know information search strategies & & 0.63 & & & & & 0.60 & & & & & \\
\hline & 9 & Assess quality of information & & & & & 0.69 & & & & 0.72 & & & \\
\hline 들 & 10 & Recognize author's ideas & & & & & 0.60 & & & & 0.64 & & & \\
\hline$\frac{\pi}{\frac{\pi}{\pi}}$ & 11 & Know tipology of information sources & & & & & 0.72 & & & & 0.82 & & & \\
\hline 党 & 12 & Determine whether an information is updated & & & & & & & & & & & & \\
\hline & 13 & Know most relevant authors-institutions & & & & & & & & & & & & \\
\hline & 14 & Schematise-abstract information & & & & & & & & & & 0.62 & & \\
\hline D & 15 & Recognise text structure & & & 0.77 & & & & & & & 0.71 & & \\
\hline 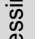 & 16 & Use database managers & & & 0.57 & & & & & & & & & 0.67 \\
\hline ర్ & 17 & Use bibliographic reference managers & & & 0.69 & & & & & & & & & 0.61 \\
\hline ¿ & 18 & Handle statistical programs - spreadsheets & & & & & & & & & & & & 0.64 \\
\hline & 19 & Install computer programs & & & & & & & & & & & & \\
\hline & 20 & Communicate in public & 0.68 & & & & & & & 0.66 & & & & \\
\hline 들 & 21 & Communicate in other languages & & & & & & 0.68 & & 0.66 & & & & \\
\hline 苋 & 22 & Write a document & & & & & & 0.65 & & 0.62 & & & & \\
\hline క气 & 23 & Know the code of ethics in academic field & & & & & & & & & & & & \\
\hline$\stackrel{\xi}{\xi}$ & 24 & Know laws on information use -intellectual property & & & & & & & 0.68 & & & & & \\
\hline ¿े & 25 & Create academic presentations & 0.74 & & & & & & & 0.64 & & & & \\
\hline & 26 & Disseminate information on the Internet & & & & & & & & & & & & \\
\hline & & Explained variance $\%$ cumulative & 35.86 & 43.24 & 48.37 & 53.14 & 57.54 & 61.75 & 22.68 & 39.92 & 45.23 & 50.38 & 54.68 & 58.69 \\
\hline & & Eigenvalue & 4.124 & 1.919 & 1.335 & 1.239 & 1.153 & 1.085 & 3.294 & 1.885 & 1.381 & 1.339 & 1.114 & 1.046 \\
\hline
\end{tabular}

Table 8: Actual knowledge (KN) factors on IL competencies by gender. Sequenced by order of explained variance

Concerning perceptions (BI and SE) on IL competencies, no pattern that clearly differentiates genders is uncovered in the latent models. However, some gender differences have been located in the objective dimension of actual knowledge (KN) on the same competencies.

\subsection{Summary of findings}

As for categories and dimensions, searching and evaluation of the information on the part of students provides similar mean scores among females and males in all dimensions -BI, SE and KN-. In processing, statistically significant gender differences in 
SE and KN dimensions do appear, with higher scores for men. In communication, significant differences in KN dimension, women scoring higher.

Considering the various academic degrees taken into consideration, significant gender differences are found in almost all categories and dimensions, with the exceptions of SE of evaluation and BI of communication in males, and BI of processing among females.

As far as latent structures are concerned, their configuration in each of the three dimensions - BI, SE, and KN- and in each gender has been distinguished. As far as BI is concerned, the factors fit three of the categories foreseen in the tools -searching, evaluation and processing-, although their order of importance varies between women and men. It is in the remaining category, that of communication, where deployments of three and two factors for men and women respectively arise. The two common factors related to communication and dissemination - are composed of the same competencies, although their relative importance is different. In the case of women, this communication factor -composed of three competencies- is the most important. The women surveyed consider their awareness of the importance of competencies related to the communication of information to be a priority. Men, on the other hand, attach greater importance to competencies related to the evaluation of information.

As for SE, the categories of searching, evaluation and processing, in the same order of importance, are faithfully reproduced in the factor analyses carried out for both genders. Here too, as in the BI dimension, the competencies of the communication category are deployed in three factors - relating to communication, ethics and the presentation of 
information - which are common to men and women, although their relative importance differs slightly.

It is in the KN dimension that the latent factor structure offers the greatest gender differences. In both genders, the search category is broken down into two factors, relating to actual knowledge of search strategies and the use of information. The only category that is faithfully reflected as a factor is that of evaluation. Processing does split up for the group of women, who distinguish between human processing and technological processing. Communication also unfolds, although with very different components in each gender. The only factor that draws on competencies belonging to two categories, search and communication, arises in this KN dimension (Figure 2).

\section{Discussion}

The discussion, from both superficial and deep standpoints, aims to detect students' strengths and weaknesses, including suggestions for them to raise its affective and cognitive levels on IL competencies. It is also intended to spot significant differences from this prevailing gender perspective.

Male and female students identify themselves with information computer practice in different ways, females being more self-criticising. Indeed, Lim and Kwon (2010) remark that previous studies reveal that women tend to rate their online skills lower than men, though there are no apparent gender difference in the competency to find information on the web (Hargittai and Shafer 2006). In related studies, male students had a higher self-perceived sense of computer self-efficacy than girls (Abbiss 2008; Ioanna Vekiri and Chronaki 2008). Enochsson (2005) offers similar results regarding confidence: males 
exhibited their technological knowledge and used technology language more than girls, though both male and female students showed the same level of interest in technology.

When comparing BI, SE and KN scales, no significant gender differences were found in the searching and evaluation categories. In the processing category, significant differences regarding gender were uncovered in SE and KN scales. Lastly, in the communication-dissemination category there are significant differences, but only on the KN scale. As for degrees, gender differences arise between almost all of them, which are significant in a large majority of categories and dimensions.

\subsection{Gender similarities and differences}

Since the research has developed a considerable number of factor analyses, a summary on the twenty-six competencies and the corresponding factors in each dimension and gender is provided (Figure 2). The ideal situation would be the absence of empty spaces in the above-mentioned table, that is to say, all competencies loading in some factor, included all gender and dimension. At this point, a distinction between main (F1) and secondary factors (f2, f3, f4, f5, f6) is necessary, as the high explained variance of the first gives them noticeably superior prominence (tables $6,7,8)$. The composition of these main factors (F1) poses a significant argument for discussion. These are placed in the following categories and dimension-gender: searching (SE-M) and (SE-F); communication (BI-F) and (KN-M); searching-communication (KN-F); and evaluation (BI-M). This result ties in with the findings obtained by Lim and Kwon (2010). 
Competency

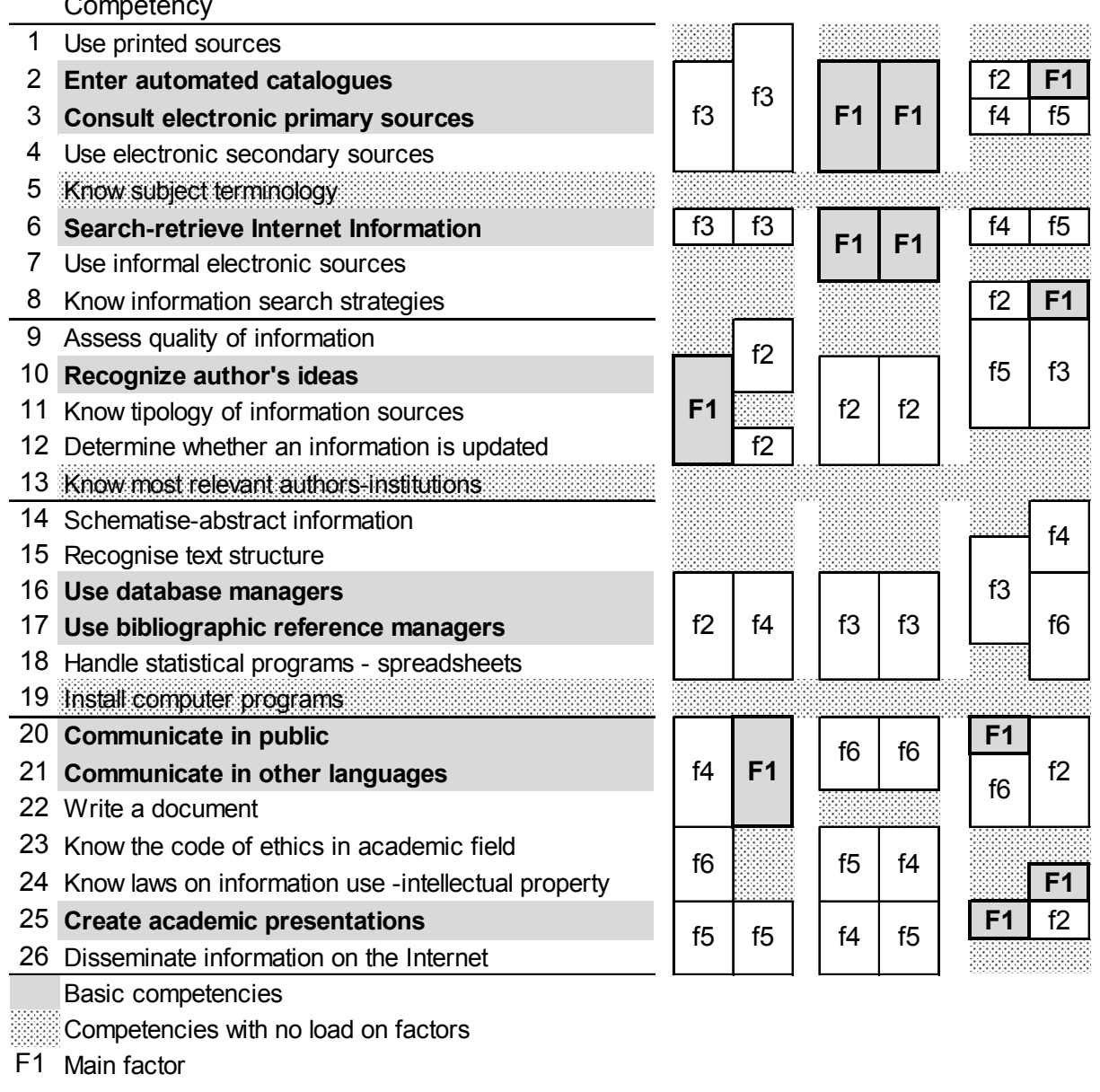

Figure 2. A summary of competency-based factors loading, by dimension and gender.

This summary table also makes it possible to discover in detail the strengths and weaknesses of the students in relation to the different competencies. While the strengths derive from the presence in the factors of these informational skills, the weaknesses have to do with their absence.

- Strengths common to all dimensions. Applied to the different dimensions and genders, factor analyses unveil nine competencies that are part of each of the six resulting latent frameworks. Despite the variability in their factorial load, their level of 
commonality make them to be an essential type of IL competencies, apart from gender or any other condition. These basic, core, competencies are: searching -enter automated catalogues, consulting and using electronic sources of primary information, and searching for and retrieve Internet information-; evaluation -recognising the author's ideas within the text-; processing -using database managers, and using bibliographic reference managers; and communication-dissemination -communicating in public, communicating in other languages, and creating academic presentations (Figure 2). Other fourteen competencies, regularly distributed among the four categories, do not show such inter-dimension strength, but are also indispensable IL competencies.

- Weaknesses common to all dimensions. On the other side, three competencies do not load in any of the factors, regardless of dimension or gender. They are the following: know subject terminology, know most relevant author-institutions, and install computer programs; each one is located in a different category. These three competencies require improvements in all three dimensions: awareness of their importance, self-efficacy, and actual knowledge about them.

- Common weaknesses in BI. They affect the following four competencies: use informal electronic sources, know information search strategies, schematize-abstract information, and recognize text structure. Due to the lack of motivation in these competencies, which affects both genders, awareness-raising sessions on their importance are recommended.

- Common weaknesses in SE. They refer to the following competencies: use printed sources, know information search strategies, assess quality of information, schematizeabstract information, recognize text structure, and write a document. Given the lack of 
self-esteem in the use of these skills, awareness-raising sessions are recommended to encourage them.

- Common weaknesses in KN. They affect the five competencies that do not contribute to factor configurations concerning actual knowledge (KN): use printed sources, use electronic sources, use informal electronic sources, determine whether information is updated, and know the code of ethics in the academic field. This result reflects the cognitive weaknesses of students in relation to such competencies. To improve these deficiencies, instructional sessions are proposed for all students alike.

- Gender weaknesses in BI and SE. There are two competencies - use printed sources, and assess quality of information- in which the BI values provided by male students are not sufficient to contribute to the factorial configuration on this scale. To improve their informational status, these students should raise awareness of their importance. On the other hand, there are three other competencies -know typology of information sources, know the code of ethics in academic field, and know the laws on information use-intellectual property- in which the values (BI) provided by female students do not contribute sufficiently to the factorial configuration. They should therefore seek to increase their awareness of the importance of these competencies. With regard to the SE dimension, there are no factorial absences affecting only one gender.

- Gender weaknesses in KN. They only affect male students, and refer to three competencies -schematize and abstract information, handle statistical programs spreadsheets, and know the laws on the information use and intellectual property-. 
Among these students, efforts should be made to increase the levels of actual knowledge about these competencies.

- Strengths and weaknesses in competency categories. From the latent perspective, the search and communication categories are the most relevant, as each of them is endowed with three main factors, although one of them is shared. This is the factor related to $\mathrm{KN}$ in female students, precisely the one that explains the least variance. The evaluation category contains only one main factor. However, no main factor is based on the competencies of the information processing category, in any dimension and gender. To this it must be added that in this category the average SE values are remarkably low. In addition, this category contains gender differences that are statistically significant in the dimensions SE and KN. Thus, it is the weakest category and therefore in need of instructional support that fosters motivation and training in its component competencies.

\subsection{Research limitations and generalizability of the method}

The study is designed with the overall objective of comparing perceptions and levels of knowledge about IL competencies taking into account the gender of the students, in order to observe possible similarities and differences. The sample collected (2014) is representative of the participating degrees, so the results could be considered to be generalizable to the population of Social Sciences students in Spain. Even so, it would be interesting to repeat the study with a current sample, which would provide a comparative picture regarding the evolution and current characteristics of training in IL competencies by gender. All factors except one feed on a single category of IL competencies, which confirms once again the strength of the organization by categories. 
On the other hand, the inherent length limitation of a paper has not allowed a more detailed breakdown of the different degrees and competencies in relation to the gender issue.

Given the methodological-statistical rigour with which this research has been carried out, the results and, above all, the method of analysis could be extrapolated to other Higher Education environments.

\section{Conclusions}

From the field of teaching IL and knowledge management, it is relevant and necessary to explore the design of awareness-raising sessions (one-shot or longer) as well as syllabus for classes already present in the curricula that could help to incorporate the gender perspective into the classroom. This would help overcome possible stereotypes and contribute to the construction of an all-inclusive perspective that fosters an awareness of the value of equality.

In relation to the IL competencies of the sample studied, a number of strengths and weaknesses were found, as well as some gender differences. It has been proven that these circumstances affect the three scales considered: motivation, self-efficacy and real knowledge of the students. While in the self-efficacy (SE) dimension, the detected latent structures lead to very similar configurations in both genders, this degree of homogeneity decreases slightly in the belief-in-importance (BI) scale, although both structures are quite precisely adapted to the factorial configuration by categories. But it is in the current knowledge scale $(\mathrm{KN})$ where the differences between male and female students are most striking. In short, while male students prioritize the importance of assessment skills and consider themselves as more prepared in search skills, those that 
they really dominate the most from a cognitive point of view belong to the category of communication. On the other hand, while female students prioritize the importance of communication skills and consider themselves as more prepared in search skills, the skills that they really dominate the most from the cognitive point of view belong to both search and communication categories.

The impact on the improvement of affective (BI and SE) and cognitive (KN) conditions of students in relation to IL competencies would contribute to the progressive regularisation of these detected differences. To this end, the study puts forward a series of proposals that affect, rather than the strengths of the students, their weaknesses or shortcomings, since it is only from the latter that real improvements can be achieved. For example, there is a clear need to improve the levels of self-efficacy of students in all categories and dimensions. In the discussion section such activities have already been proposed regarding genders, the different dimensions, and both the affective (awareness sessions) and cognitive (classes) aspects, focused on the weakest competencies.

In any case, this research is still a starting point, and a more in-depth analysis is required in order to look in greater detail at the different degrees and competencies. Given the relevance of acquiring information competencies in higher education, any approach that can provide new perspectives that result in educational improvements is important. In this regard, observing the gender variable (as one of a number of possible sociological variables) is a path that is open to further analyses that will ultimately lead to proposals for educational improvement from an applied and operational perspective. 


\section{Acknowledgments}

The authors are grateful to those who contributed to the research at various phases, and to the Spanish Ministry of Science and Innovation, that funded the research project EVAL-CI (Assessment of information competencies of social science students in higher education: Designing web tools and an e-learning 2.0 training proposal) (EDU201129290). 


\section{References}

Abbiss, J. (2008). Rethinking the 'problem' of gender and IT schooling: Discourses in literature. Gender and Education, 20(2), 153-165.

ACRL. Association of College \& Research Libraries (2000). Information Literacy Competency Standards for Higher Education. Retrieved July 20, 2019 from https://alair.ala.org/handle/11213/7668.

ALA/ACRL/Women \& Gender Studies Section. Retrieved September 29, 2017 from http://libr.org/wss/.

Association of College and Research Libraries Women and Gender Studies Section. October 2012. Research Agenda for Women and Gender Studies Librarianship. Retrieved October 4, 2017 from http://www.libr.org/wgss/committees/research/resagenda.html.

Association of College and Research Libraries Women and Gender Studies Section. October 2012. Information Literacy and Women and Gender Studies in Higher Education. Retrieved October 4, 2017 from http://libr.org/wgss/committees/research/resagenda_files/infoliteracy.html.

Baro, E. \& Fyneman, B. (2009). Information literacy among undergraduate students in Niger Delta University. The Electronic Library, 27(4), 659-675.

Bartlett, M. S. (1950). Tests of significance in factor analysis. British Journal of Psychology, 3(2), 77-85.

Bawden, D. \& Robinson, L. (2009). The dark side of information: overload, anxiety and other paradoxes and pathologies. Journal of Information Science, 35(2), 180-191.

Broidy, E. (2007). Gender and the politics of information: Reflections on bringing the library into the classroom. Library Trends, 56(2), 494-508.

Burdick, T. A. (1996). Success and diversity in information seeking: Gender and the information search styles model. School Library Media Quarterly, 25(1), 19-26.

Chen, K. \& Lin, P. (2011). Information literacy in university library user education. Aslib Proceedings, 63(4), 399-418.

Cho, E., \& Kim, S. (2015). Cronbach's coefficient alpha: Well known but poorly understood. Organizational Research Methods, 18(2), 207-230.

Clark, M., Coward, C., Rothschild, C., Reynal, L. de, \& Richter, B. (2017). Towards a mobile information literacy framework: Rethinking information literacy in a mobile era. In iConference 2017 Proceedings (934-936). Retrieved October 10 from https://www.ideals.illinois.edu/handle/2142/96782

Dennis, N. (2001). Using inquiry methods to foster information literacy partnerships. Reference Services Review, 29(2), 122-131.

Enochsson, A. (2005). A gender perspective on Internet use: Consequences for information seeking on the net. Information Research 10(4), paper 237. Retrieved October 27, 2017 from http://InformationR.net/ir/10-4/paper237.html. 
Field, A. (2013). Discovering Statistics Using IBM SPSS Statistics. Newcastle: SAGE Publications.

Fields, A. M. (2001). Women's epistemological development: Implications for undergraduate information literacy instruction. Research Strategies, 18(3), 227-238.

Gillard, H., Mitev, N., \& Scott, S. (2007). ICT inclusion and gender: Tensions in narratives of network engineer training. The Information Society, 23(1), 19-37.

Gilley, J. (2007). Women's studies information-seeking: A state of the union address. NWSA Journal, 19(2), 220-229.

Golian, L. M., \& Pellen, R. M. (1996). Helping re-entry women develop library technical skills and research strategies. Feminist Collections: A Quarterly of Women's Studies Resources, 17(2), 44-47.

Grizzle, A. (2014). Enlisting media and informational literacy for gender equality and women's empowerment. In A. Vega Montiel (Ed.), Media and Gender: A Scholarly Agenda for the Global Alliance on Gender (79-91). Paris: UNESCO \& IAMCR. Retrieved October 8, 2017 from http://www.unesco.org/new/fileadmin/MULTIMEDIA/HQ/CI/CI/pdf/publications/ga mag_research_agenda_grizzle.pdf

Grizzle, A., Moore, P., Dezuanni, M., Asthana, S., Wilson, C., Banda, F., \& Onumah, C. (2014). Media and information literacy: Policy and strategy guidelines. Paris: UNESCO.

Hair, J.F., Black, W.C., Babin, B.J., \& Anderson, R.E. (2010). Multivariate Data Analysis: A Global Perspective. $7^{\text {th }}$ edition. New Jersey: Pearson Prentice Hall.

Hargittai, E., \& Shafer, S. (2006). Differences in actual and perceived online skills: The role of gender. Social Science Quarterly, 87(2), 432-448.

Huston, M., \& Yribar, R. (1991). Women's knowing and knowing women: Instructional lessons from collection development. Research Strategies, 9(2), 77-86.

Ioanna Vekiri, I., \& Chronaki, A. (2008). Gender issues in technology use: Perceived social support, computer self-efficacy and value beliefs, and computer use beyond school. Computers \& Education, 51, 1392-1404.

Julien, H., Gross, M., \& Latham, D. (2018). Survey of information literacy instructional practices in US academic libraries. College \& Research Libraries, 79(2), 179-199.

Kaiser, H. F. (1974). An index of factorial simplicity. Psychometrika, 39, 31-36.

Kwon, N., \& Song, H. (2011). Personality traits, gender, and information competency among college students. Malaysian Journal of Library \& Information Science, 16(1), 87107.

Lee, A. Y. L. (2010). Media education: Definitions, approaches and development around the globe. New Horizons in Education, 58(3), 1-13.

Lim, S., \& Kwon, N. (2010). Gender differences in information behavior concerning Wikipedia, an unorthodox information source. Library \& Information Science Research, 32(3), 212-220. 
Lin, S., Shih, T., \& Lu, R. (2013). ICT proficiency and gender: a validation on training and development. International Journal of Technology and Design Education, 23(2), 179190.

Liu, T., \& Sun, H. (2012). Gender differences on information literacy of science and engineering undergraduates. International Journal of Modern Education and Computer Science, 2, 23-30.

Nunnally, J. (1978). Psychometric Theory. $2^{\text {nd }}$ edition. New York: McGraw-Hill.

Pinto, M. (2010). Design of the IL-HUMASS survey on information literacy in higher education: a self-assessment approach. Journal of Information Science, 36(1), 86-103.

Pinto, M. (2011). An approach to the internal facet of information literacy using the IL-HUMASS survey. Journal of Academic Library, 37(2), 145-154.

Pinto, M., \& Fernández-Pascual, R. (2017). A diagnosis of the levels of information literacy competency among social sciences undergraduates. Portal: Libraries and the Academy, 17(3), 569-593.

Pinto, M., Fernández-Pascual, R., \& Puertas, S. (2016). Undergraduates' information literacy competency: A pilot study of assessment tools based on a latent trait model. Library \& Information Science Research, 38(2), 180-189.

Radeloff, C. L., \& Bergman, B. J. (2009). Global perspectives: Developing media literacy skills to advance critical thinking. Feminist Teacher, 19(2), 168-171.

Roy Dholakia, R. (2006). Gender and IT in the household: Evolving patterns of Internet use in the United States. The Information Society, 22(4), 231-240.

Simoes, S., \& Gray, S. (2009). Combining academic service-learning and information literacy: A new framework for an introductory women's studies course. The Scholarship of Teaching and Learning at EMU 2, Article 8. Retrieved 30 December, 2017 from http://commons.emich.edu/sotl/vol2/iss1/8.

Steinerová, J., \& Susol, J. (2007). Users' information behaviour: A gender perspective. Information Research, 12(3). Retrieved 24 November, 2017 from http://www.informationr.net/ir/12-3/paper320.html.

Taber, K. S. (2018). The use of Cronbach's alpha when developing and reporting research instruments in science education. Research in Science Education, 48(6), 12731296.

Taylor, A., \& Dalal, H. A. (2017). Gender and information literacy: Evaluation of gender differences in a student survey of information sources. College \& Research Libraries, 78(1), 90-113.

UNESCO (2009). Education indicators. Technical guidelines. UNESCO: Institute for Statistics. Retrieved October 8, 2017 from http://uis.unesco.org/sites/default/files/documents/education-indicators-technicalguidelines-en_0.pdf.

Volman, M. (1997). Gender-related effects of computer and information literacy education. Journal of Curriculum Studies, 29(3), 315-328. 
Weeg, B. (1997). Library skill development in a women's studies course. Feminist Collections: A Quarterly of Women's Studies Resources, 18(3), 11-13.

Wilkinson, C. W. (2004). Stronger students, better research: Information literacy in the women's studies classroom. Feminist Collections: A Quarterly of Women's Studies Resources, 25(4), 1-5.

Wilkinson, C. W. (2006). Learning from student learning: A librarian-instructor's view of her information literacy class. Feminist Collections: A Quarterly of Women's Studies Resources, 28(1), 9-16. 
ANNEX: ILHumass Test and descriptive results

\begin{tabular}{|c|c|c|c|}
\hline With regard to ... & $\begin{array}{l}\text { Belief-in- } \\
\text { Importance }\end{array}$ & Self-efficacy & Source of learning \\
\hline COMPETENCIES-ABILITIES & $\begin{array}{c}\text { Low } \\
123456789\end{array}$ & 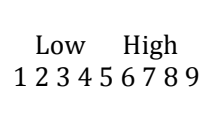 & $\begin{array}{c}\text { Class; Courses; } \\
\text { Library; Self-learning; } \\
\text { Others }\end{array}$ \\
\hline \multicolumn{4}{|l|}{ SEARCHING } \\
\hline \multicolumn{4}{|l|}{ 1. to use printed sources of information (books, papers, etc.) } \\
\hline \multicolumn{4}{|l|}{ 2. to enter and use automated catalogues } \\
\hline \multicolumn{4}{|l|}{$\begin{array}{l}\text { 3. to consult and use electronic sources of primary information } \\
\text { (journals, etc.) }\end{array}$} \\
\hline \multicolumn{4}{|l|}{ 4. to use electronic sources of secondary information (databases, etc.) } \\
\hline \multicolumn{4}{|l|}{ 5. to know the terminology of your subject } \\
\hline \multicolumn{4}{|l|}{$\begin{array}{l}\text { 6. to search for and retrieve Internet information (advanced searches, } \\
\text { directories, portals, ) }\end{array}$} \\
\hline \multicolumn{4}{|l|}{$\begin{array}{l}\text { 7. to use informal electronic sources of information (blogs, discussion } \\
\text { lists, etc.) }\end{array}$} \\
\hline \multicolumn{4}{|l|}{$\begin{array}{l}\text { 8. to know information search strategies (descriptors, Boolean } \\
\text { operators, etc.) }\end{array}$} \\
\hline \multicolumn{4}{|l|}{ EVALUATION } \\
\hline \multicolumn{4}{|l|}{ 9. to assess the quality of information resources } \\
\hline \multicolumn{4}{|l|}{ 10. to recognise the author's ideas within the text } \\
\hline \multicolumn{4}{|l|}{$\begin{array}{l}\text { 11. to know the typology of scientific information sources (thesis, } \\
\text { proceedings, etc.) }\end{array}$} \\
\hline \multicolumn{4}{|l|}{ 12. to determine whether an information resource is updated } \\
\hline \multicolumn{4}{|l|}{$\begin{array}{l}\text { 13. to know the most relevant authors and institutions within your } \\
\text { subject area }\end{array}$} \\
\hline \multicolumn{4}{|l|}{ PROCESSING } \\
\hline \multicolumn{4}{|l|}{ 14. to schematise and abstract information } \\
\hline \multicolumn{4}{|l|}{ 15. to recognise text structure } \\
\hline \multicolumn{4}{|l|}{ 16. to use database managers (Access, MySQL, etc.) } \\
\hline \multicolumn{4}{|l|}{$\begin{array}{l}\text { 17. to use bibliographic reference managers (Endnote, Reference } \\
\text { Manager, etc.) }\end{array}$} \\
\hline \multicolumn{4}{|l|}{ 18. to handle statistical programs and spreadsheets (SPSS, Excel, etc.) } \\
\hline \multicolumn{4}{|l|}{ 19. to install computer programs } \\
\hline \multicolumn{4}{|l|}{ COMMUNICATION AND DISSEMINATION } \\
\hline \multicolumn{4}{|l|}{ 20. to communicate in public } \\
\hline \multicolumn{4}{|l|}{ 21. to communicate in other languages } \\
\hline \multicolumn{4}{|l|}{ 22. to write a document (report, academic work, etc.) } \\
\hline \multicolumn{4}{|l|}{ 23. to know the code of ethics in your academic/professional field } \\
\hline \multicolumn{4}{|l|}{ 24. to know the laws on the use of information and intellectual property } \\
\hline \multicolumn{4}{|l|}{ 25. to create academic presentations (PowerPoint, etc.) } \\
\hline 26. to disseminate information on the Internet (webs, blogs, etc.) & & & \\
\hline
\end{tabular}




\begin{tabular}{|c|c|c|c|c|c|c|c|c|c|}
\hline \multirow[b]{3}{*}{ Degree } & & \multicolumn{8}{|c|}{$\mathrm{BI}$} \\
\hline & & \multicolumn{2}{|c|}{ Searching } & \multicolumn{2}{|c|}{ Evaluation } & \multicolumn{2}{|c|}{ Processing } & \multicolumn{2}{|c|}{ Communication/Disseminatior } \\
\hline & & Mean & Std. Dev. & Mean & Std. Dev. & Mean & Std. Dev. & Mean & Std. Dev. \\
\hline \multirow[t]{3}{*}{ Audiovisual Communication } & Male & 7.2175 & .89482 & 7.6420 & .87677 & 6.8100 & 1.34653 & 7.9014 & .89978 \\
\hline & Female & 7.6913 & .76451 & 8.0102 & .83252 & 7.5867 & .92137 & 8.3980 & .61274 \\
\hline & Total & 7.4520 & .86405 & 7.8242 & .87272 & 7.1944 & 1.21686 & 8.1472 & .80849 \\
\hline \multirow[t]{3}{*}{ Education } & Male & 7.3491 & .84753 & 7.6044 & .95993 & 7.3025 & 1.01260 & 7.9651 & .73994 \\
\hline & Female & 7.6638 & .84836 & 7.8783 & .98727 & 7.5950 & 1.00955 & 8.2444 & .68527 \\
\hline & Total & 7.5490 & .86039 & 7.7784 & .98496 & 7.4883 & 1.01910 & 8.1425 & .71745 \\
\hline \multirow[t]{3}{*}{ Information Science } & Male & 7.7926 & .94966 & 7.6909 & .99623 & 7.4318 & .96134 & 7.8182 & .94126 \\
\hline & Female & 7.9263 & .85528 & 7.9436 & .95992 & 7.7821 & .82455 & 7.9927 & .86848 \\
\hline & Total & 7.8781 & .88890 & 7.8525 & .97669 & 7.6557 & .88859 & 7.9297 & .89549 \\
\hline \multirow[t]{3}{*}{ Journalism } & Male & 7.2384 & .81926 & 7.5837 & .93669 & 6.8837 & 1.05968 & 8.0199 & .85100 \\
\hline & Female & 7.8033 & .82616 & 8.0960 & .83985 & 7.4511 & 1.02441 & 8.4810 & .63466 \\
\hline & Total & 7.5975 & .86589 & 7.9093 & .90863 & 7.2444 & 1.07071 & 8.3130 & .75284 \\
\hline \multirow[t]{3}{*}{ Pedagogy } & Male & 7.7330 & .75524 & 7.9091 & .81819 & 7.6364 & .93808 & 8.3117 & .51534 \\
\hline & Female & 7.5852 & 1.00466 & 7.8374 & 1.11869 & 7.5037 & 1.06544 & 8.0942 & .91924 \\
\hline & Total & 7.6139 & .95993 & 7.8513 & 1.06395 & 7.5295 & 1.03922 & 8.1365 & .85808 \\
\hline \multirow[t]{3}{*}{ Psychology } & Male & 7.2679 & .96374 & 7.7810 & .99247 & 7.1865 & 1.08526 & 7.8605 & .85394 \\
\hline & Female & 7.7576 & .87243 & 8.0221 & .93331 & 7.6142 & .98422 & 8.2612 & .68823 \\
\hline & Total & 7.6654 & .90857 & 7.9767 & .94716 & 7.5336 & 1.01539 & 8.1858 & .73714 \\
\hline \multirow[t]{3}{*}{ Social Work } & Male & 7.1359 & 1.33459 & 7.5217 & 1.51686 & 6.9928 & 1.27869 & 7.5590 & 1.32614 \\
\hline & Female & 7.5581 & 1.05401 & 7.8035 & 1.13978 & 7.2573 & 1.29634 & 8.0865 & .93274 \\
\hline & Total & 7.4872 & 1.11188 & 7.7562 & 1.20945 & 7.2129 & 1.29253 & 7.9979 & 1.02299 \\
\hline \multirow[t]{3}{*}{ Tourism } & Male & 7.1016 & .99489 & 7.4208 & .94733 & 7.2986 & .97726 & 7.9911 & .67933 \\
\hline & Female & 7.4297 & 1.02979 & 7.5984 & 1.16389 & 7.5742 & 1.08393 & 8.1205 & .94275 \\
\hline & Total & 7.3402 & 1.02806 & 7.5500 & 1.10923 & 7.4991 & 1.06032 & 8.0852 & .87880 \\
\hline
\end{tabular}

Table 1A: Descriptive results of $\mathrm{BI}$ dimension by category and gender

\begin{tabular}{|c|c|c|c|c|c|c|c|c|c|}
\hline \multirow[b]{3}{*}{ Degree } & & \multicolumn{8}{|c|}{ SE } \\
\hline & & \multicolumn{2}{|c|}{ Searching } & \multicolumn{2}{|c|}{ Evaluation } & \multicolumn{2}{|c|}{ Processing } & \multicolumn{2}{|c|}{ Communication/Dissemination } \\
\hline & & Mean & Std. Dev. & Mean & Std. Dev. & Mean & Std. Dev. & Mean & Std. Dev. \\
\hline \multirow[t]{3}{*}{ Audiovisual Communication } & Male & 6.5350 & 1.11409 & 6.6080 & 1.19390 & 6.1083 & 1.17431 & 6.8114 & 1.05680 \\
\hline & Female & 6.6901 & 1.04200 & 6.7592 & .95419 & 6.2177 & 1.16492 & 7.0831 & .95731 \\
\hline & Total & 6.6117 & 1.07907 & 6.6828 & 1.08183 & 6.1625 & 1.16799 & 6.9459 & 1.01540 \\
\hline \multirow[t]{3}{*}{ Education } & Male & 6.6593 & 1.06060 & 6.7200 & .93304 & 6.4728 & 1.15348 & 6.8582 & .98504 \\
\hline & Female & 6.4638 & 1.10350 & 6.5923 & 1.12839 & 6.1000 & 1.27547 & 6.7964 & .98698 \\
\hline & Total & 6.5351 & 1.09067 & 6.6389 & 1.06178 & 6.2360 & 1.24383 & 6.8189 & .98539 \\
\hline \multirow[t]{3}{*}{ Information Science } & Male & 6.8920 & .97669 & 6.7409 & 1.08227 & 6.7917 & .89582 & 6.5682 & 1.07059 \\
\hline & Female & 7.0865 & .92325 & 7.0154 & 1.00739 & 6.6966 & .89036 & 6.7747 & .85946 \\
\hline & Total & 7.0164 & .94352 & 6.9164 & 1.03902 & 6.7309 & .88981 & 6.7002 & .94197 \\
\hline \multirow[t]{3}{*}{ Journalism } & Male & 6.4491 & 1.04870 & 6.7767 & .93226 & 5.9477 & 1.18852 & 6.9020 & .95474 \\
\hline & Female & 6.8375 & .94487 & 7.1707 & .93648 & 6.2022 & 1.11922 & 7.2257 & .91320 \\
\hline & Total & 6.6960 & .99947 & 7.0271 & .95210 & 6.1095 & 1.14902 & 7.1077 & .93959 \\
\hline
\end{tabular}




\begin{tabular}{|c|c|c|c|c|c|c|c|c|c|}
\hline \multirow[t]{3}{*}{ Pedagogy } & Male & 7.1250 & .97208 & 6.9727 & 1.15189 & 6.7955 & 1.13381 & 7.3636 & .60082 \\
\hline & Female & 6.4588 & .99461 & 6.4703 & 1.07098 & 6.0952 & 1.14346 & 6.5620 & .95519 \\
\hline & Total & 6.5885 & 1.02094 & 6.5681 & 1.10018 & 6.2316 & 1.17015 & 6.7181 & .95000 \\
\hline \multirow[t]{3}{*}{ Psychology } & Male & 6.6399 & 1.07110 & 6.7238 & .92230 & 6.2976 & 1.31725 & 6.6327 & 1.24065 \\
\hline & Female & 6.4289 & 1.14679 & 6.4486 & 1.24055 & 6.0700 & 1.24077 & 6.6125 & 1.07597 \\
\hline & Total & 6.4686 & 1.13360 & 6.5004 & 1.19018 & 6.1129 & 1.25566 & 6.6163 & 1.10590 \\
\hline \multirow[t]{3}{*}{ Social Work } & Male & 6.3804 & 1.12024 & 6.6348 & .89980 & 6.3551 & 1.15831 & 6.6522 & .96874 \\
\hline & Female & 6.0954 & 1.24571 & 6.2421 & 1.25943 & 5.8056 & 1.27816 & 6.2920 & 1.10041 \\
\hline & Total & 6.1432 & 1.22630 & 6.3080 & 1.21268 & 5.8978 & 1.27159 & 6.3525 & 1.08452 \\
\hline \multirow[t]{3}{*}{ Tourism } & Male & 6.4766 & .96813 & 6.6375 & .91944 & 6.4444 & .99665 & 6.9018 & .78032 \\
\hline & Female & 6.5313 & 1.11946 & 6.5391 & 1.10903 & 6.4609 & 1.08285 & 6.8158 & 1.10237 \\
\hline & Total & 6.5163 & 1.07786 & 6.5659 & 1.05904 & 6.4564 & 1.05725 & 6.8393 & 1.02319 \\
\hline
\end{tabular}

Table 2A: Descriptive results of SE dimension by category and gender

\begin{tabular}{|c|c|c|c|c|c|c|c|c|c|}
\hline \multirow[b]{3}{*}{ Degree } & & \multicolumn{8}{|c|}{ KN } \\
\hline & & \multicolumn{2}{|c|}{ Searching } & \multicolumn{2}{|c|}{ Evaluation } & \multicolumn{2}{|c|}{ Processing } & \multicolumn{2}{|c|}{ Communication/Dissemination } \\
\hline & & Mean & Std. Dev. & Mean & Std. Dev. & Mean & Std. Dev. & Mean & Std. Dev. \\
\hline \multirow[t]{3}{*}{ Audiovisual Communication } & Male & 6.9400 & 1.27778 & 8.3480 & .89290 & 6.4033 & 1.37991 & 8.3600 & .86540 \\
\hline & Female & 6.8112 & 1.27882 & 8.4531 & .82315 & 6.0544 & 1.39192 & 8.5015 & .80322 \\
\hline & Total & 6.8763 & 1.27668 & 8.4000 & .85852 & 6.2306 & 1.39336 & 8.4300 & .83610 \\
\hline \multirow[t]{3}{*}{ Education } & Male & 6.5870 & 1.33177 & 8.0726 & 1.02232 & 6.0222 & 1.37449 & 7.6963 & 1.15432 \\
\hline & Female & 6.4266 & 1.26811 & 8.1396 & 1.10690 & 5.6567 & 1.30103 & 8.0286 & 1.03832 \\
\hline & Total & 6.4851 & 1.29222 & 8.1151 & 1.07589 & 5.7901 & 1.33810 & 7.9073 & 1.09234 \\
\hline \multirow[t]{3}{*}{ Information Science } & Male & 8.0909 & .72755 & 8.5727 & 60014 & 7.1742 & 96579 & 8.0390 & .96466 \\
\hline & Female & 8.1538 & .86624 & 8.4718 & 65582 & 7.1068 & 1.15532 & 8.4212 & .72803 \\
\hline & Total & 8.1311 & .81642 & 8.5082 & 63566 & 7.1311 & 1.08716 & 8.2834 & 83784 \\
\hline \multirow[t]{3}{*}{ Journalism } & Male & 7.0203 & 1.39969 & 8.1395 & 1.25673 & 6.3798 & 1.45716 & 8.1296 & 1.14110 \\
\hline & Female & 7.1067 & 1.15471 & 8.4747 & . 97995 & 6.1600 & 1.21617 & 8.3410 & .74088 \\
\hline & Total & 7.0752 & 1.24730 & 8.3525 & 1.09829 & 6.2401 & 1.31036 & 8.2639 & 91071 \\
\hline \multirow[t]{3}{*}{ Pedagogy } & Male & 6.8295 & 1.14794 & 8.3636 & .77739 & 6.0758 & 1.63924 & 8.0000 & 1.12486 \\
\hline & Female & 6.6016 & 1.15589 & 8.3011 & 89957 & 5.6117 & 1.37371 & 7.9984 & .81078 \\
\hline & Total & 6.6460 & 1.15279 & 8.3133 & .87418 & 5.7021 & 1.43328 & 7.9987 & .87492 \\
\hline \multirow[t]{3}{*}{ Psychology } & Male & 6.9226 & 1.11734 & 8.6667 & 56511 & 5.9127 & 1.55488 & 8.2245 & .94716 \\
\hline & Female & 6.9751 & 1.22506 & 8.5138 & .75930 & 5.7993 & 1.32016 & 8.0245 & .94567 \\
\hline & Total & 6.9652 & 1.20326 & 8.5426 & .72803 & 5.8206 & 1.36440 & 8.0621 & .94706 \\
\hline \multirow[t]{3}{*}{ Social Work } & Male & 7.1739 & 1.09605 & 8.3565 & . 77918 & 5.7681 & 1.64051 & 7.5714 & 1.32340 \\
\hline & Female & 6.3882 & 1.27783 & 8.1404 & 1.12034 & 5.1316 & 1.28880 & 7.8195 & 1.01888 \\
\hline & Total & 6.5201 & 1.27981 & 8.1766 & 1.07130 & 5.2384 & 1.36838 & 7.7779 & 1.07449 \\
\hline \multirow[t]{3}{*}{ Tourism } & Male & 6.4688 & 1.14695 & 8.1667 & 1.08791 & 6.8194 & 1.34737 & 7.7857 & .96396 \\
\hline & Female & 6.5781 & 1.24101 & 8.1156 & 1.09130 & 5.7839 & 1.43545 & 7.8259 & .89653 \\
\hline & Total & 6.5483 & 1.21382 & 8.1295 & 1.08750 & 6.0663 & 1.48218 & 7.8149 & .91279 \\
\hline
\end{tabular}

Table 3A: Descriptive results of $\mathrm{KN}$ dimension by category and gender 